\title{
DUKUNGAN KELUARGA DALAM UPAYA MENINGKATKAN KUALITAS HIDUP PASIEN GAGAL GINJAL KRONIK YANG MENJALANI HEMODIALISA DI RSU ROYAL PRIMA MEDAN TAHUN 2019
}

\author{
${ }^{1}$ Septiyandi Harapan, ${ }^{2}$ Elmy Ruthnita, ${ }^{3}$ Agnes Fanny, ${ }^{4}$ Nita Silaban, ${ }^{5}$ Crismis Novalinda \\ 1,2,3,4 Mahasiswa FKK Universitas Prima Indonesia Medan, Jl. Belanga No. 1 simp. Ayahanda Medan \\ ${ }^{5}$ Dosen FKK Universitas Prima Indonesia Medan, Jl. Belanga No. 1 simp. Ayahanda Medan
}

Email: ${ }^{1}$ Septiandisipayung09@gmail.com, ${ }^{2}$ ruthnitaelmy13@gmail.com, 3agnesfanycahyan@gmail.com, ${ }^{4}$ nitagalaxy807@gmail.com, ${ }^{5}$ chrismis@unprimdn.ac.id

\begin{abstract}
ABSTRAK
Hemodialisa dapat secara tidak langsung mempengaruhi kualitas hidup pasien GGK. Kualitas hidup sangat erat kaitannya dengan adanya dukungan keluarga. Dukungan keluarga yang dapat diberikan oleh keluarga antara lain penghargaan, informasi instrumental, dan emosional. GGK disebabkan oleh beberapa penyakit seperti kelainan ginjal, DM, kelainan autoimun, sedangkan komplikasi GGK adalah: edema, hipertensi, penyakit tulang dan anemia. Komplikasi GGK dapat diantisipasi dengan tindakan mengontrol tekanan darah ( hipertensi), dan menjaga pola hidup Dan biasanya bila seseorang yang telah divonis penyakit GGK akan disarankan untuk menjalani terapi hemodialisa. Tujuan penelitian ini dilakukan supaya untuk mengetahui dukungan keluarga dalam upaya meningkatkan kualitas pasien GGK yang menjalani hemodialisa di RSU Royal Prima Medan. Metode penelitian ini adalah survey analitik dengan pendekatan cross sectional(dengan memberikan sebuah kuesioner) dan menggunakan accidental sampling. Sampel yang terdapat dalam penelitian ini adalah pasien yang telah menjalani terapi hemodialisa di RSU Royal Prima Medan yang berjumlah 30 orang. Pengambilan data yang dilakukan peneliti dengan menggunakan teknik kuesioner dan diolah dengan menggunakan uji chi-square. Makah didapatkan hasil penelitian menunjukkan bahwa dukungan keluarga yang mayoritasnya baik yaitu sebanyak 20jiwa (66,7\%) dan dukungan keluarga yang minoritas tidak baik sebanyak 10 jiwa (33,3\%). Kualitas hidup mayoritas ketegori yang baik sebanyak 18 jiwa $(60 \%)$ dan kualitas hidup minoritas kurang sebanyak 5 jiwa (16,7\%). Hasil statistik dengan uji chi-square di dapatkan pvalue $=0,020<$ 0,05 .
\end{abstract}

Kata kunci: Dukungan keluarga, Kualitas hidup, GGK dan Hemodialisa.

\section{ABSTRACT}

Hemodialisa can indirectly affect the quality of life of patients GGK. Quality of life is closely associated with the presence of family support. Family support that may be provided by the family, among other awards, the instrumental, and emotional information. GGK is caused by several diseases such as kidney disorders, autoimmune disorders, DM, whereas GGK complications are: hypertension, edema, bone disease and anemia. Complications of GGK can be anticipated by the Act of controlling blood pressure (hypertension), and keep the pattern of life and normally when someone who has been convicted of GGK disease will be advised to undergo therapy hemodialisa. The purpose of this research was conducted in order to find out the family support in an effort to improve the quality of patients undergoing hemodialisa GGK in RSU Royal Prima Medan. The method of this research is a survey with cross sectional approach analytic (by providing a questionnaire) and use the accidental sampling. The samples contained in this study are patients who have undergone the therapy hemodialisa in RSU Royal Prima Medan that add up to 30 people. Data retrieval is done by researchers using the technique of questionnaires and processed using the chi-square test. Makah obtained results showed that the family support were good that is as much as 20jiwa (66.7\%) and family support that the minority is not good as much as 10 (33.3\%). Quality of life of the majority of the requirements of the good as much as 18 inhabitants (60\%) and quality of life of minorities less as much as 5 inhabitants (16.7\%). The results of the statistics by chi-square test get pvalue $=0.020<0.05$.

Keywords: family support, quality of life, GGK and Hemodialisa. 


\section{PENDAHULUAN}

GGK disebabkan oleh beberapa penyakit seperti kelainan ginjal, DM, kelainan autoimun, sedangkan komplikasi GGK adalah: edema, hipertensi, penyakit tulang dan anemia. Komplikasi GGK dapat diantisipasi dengan tindakan mengontrol tekanan darah (hipertensi), dan menjaga pola hidup (Davey, 2005)

Data $W H O$ menunjukan pasien yang menderita GG kronik maupun akut mencapai $50 \%$ sedangkan yang diketahui dan mendapatkan pengobatan hanya 25\% dan $12,5 \%$ yang terobati dengan baik.

Pada tahun 2007 telah ditemukan jumlah penderita penyakit GGK Amerika Serikat berjumlah 80.000 jiwa dan pada tahun 2010 terjadi peningkatan yang sangat cepat menjadi 660.000 jiwa. Di tahun pada tahun 2007 Indonesia juga termasuk negara yang mempunyai penderita GGK yang cukup tinggi, di temukan data penderita GGK mencapai 2.148 jiwa dan pada tahun 2008 terjadi peningkatan menjadi 2.260 jiwa yang menderita penyakit GGK (Desitasari dkk, 2014).

Riskesdes tahun 2013, frekuensi Indonesia yang menderita GGK sebesar $0,2 \%$ penduduk. Dukungan keluarga adalah sikap, tindakan, dukungan dan penerimaan keluarga terhadap keluarga yang mengalami masalah kesehatan atau sakit. Keluarga juga sangat berfungsi sebagai individu yang bersifat mendukung (baik dukungan ekonomi maupun instrumental), dan kelurga harus selalu siap memberikan pertolongan baik secara langsung maupun tidak langsung jika memang diperlukan. Kualitas hidup yang sangat baik sangat diperlukan dalam proses pengobatan dan dalam tindakan pemberian pelayanan keperawatan yang bersifat menyeluruh sehingga akan mendapatkan sebuah hasil penanganan yang sangat optimal.

Menurut survey awal yang telah dilakukan oleh peneliti pada 9 April 2019 melalui sebuah metode tindakan wawancara dengan kepala ruang Hemodialisa RSU.Royal Prima Medan beliau menyatakan dengan sangat tegas bahwa ruangan Hemodialisa RSU. Royal Prima Medan memiliki fasilitas yang sangat memadai yang dapat kita lihat dari adanya ketersedian 22 tempat tidur yang di sediakan oleh tim Hemodialisa RSU Royal Prima Medan untuk menunjang keberhasilan hemodialisa. serta disediakan juga 14 tenaga perawat sehingga dapat menjangkau sebuah keberhasilan dalam melakukan tindakan hemodialisa .Berdasarkan hasil data di bulan maret terdapat 116 orang yang menjalani tindakan Hemodialisa RSU. Royal Prima Medan.

\section{METODE}

Penelitian Survey analitik dengan pendekatan cross-sectional, untuk mengetahui hubungan variabel bebas dan variabel terikat, tempat penelitian dilakukan di RSU Royal Prima Medan. Teknik Accidental sampling, Sampel berjumlah 30 orang. Dengan menggunakan kuesioner WHOQOL-BREF uji Chi-Square dalam program SPSS.

\section{HASIL}

\section{Analisa Univariat}

Di lihat dari hasil penelitian yang dilakukan pada tanggal 26 Juli 2019, maka diperoleh hasil sebagai berikut :

Tabel 1. Gambaran Karakteristi Penderita GGK Yang Menjalani Tindakan Hemodialisa di RSU Royal Prima Medan di Tahun 2019

\begin{tabular}{llll}
\hline No & $\begin{array}{l}\text { Karakteristik } \\
\text { Responden }\end{array}$ & $\begin{array}{l}\text { Frekuensi } \\
(\mathbf{n})\end{array}$ & $\begin{array}{l}\text { Persentase } \\
(\mathbf{\%})\end{array}$ \\
\hline 1 & Umur & & \\
\hline & $21-56$ & 17 & 57 \\
\hline & $57-73$ & 13 & 43 \\
\hline & Total & $\mathbf{3 0}$ & $\mathbf{1 0 0}$ \\
\hline 2 & Jenis Kelamin & & \\
\hline & Laki-Laki & 14 & 47 \\
\hline & Perempuan & 16 & 53 \\
\hline & Total & $\mathbf{3 0}$ & $\mathbf{1 0 0}$ \\
\hline & Tabel diatas & ditemukan & gambaran
\end{tabular}
karakteristik responden mayoritas berusia 21-56 tahun sebanyak 17 jiwa (57\%), sedangkan minoritas responden berusia 57 73 tahun sebanyak 13 jiwa (43\%). Berdasarkan jenis kelamin mayoritas perempuan sebanyak 16 jiwa (53\%) dan minoritas laki-laki sebanyak 14 orang (47\%)

Tabel 2. Distribusi Frekuensi Dukungan Keluarga Penderita GGK Yang Menjalani Tindakan Hemodialisa di RSU Royal Prima Medan Tahun 2019

\begin{tabular}{llll}
\hline No & $\begin{array}{l}\text { Dukungan } \\
\text { keluarga }\end{array}$ & $\begin{array}{l}\text { Jumlah } \\
(\mathbf{n})\end{array}$ & $\begin{array}{l}\text { Persentase } \\
(\%)\end{array}$ \\
\hline
\end{tabular}




\begin{tabular}{llll}
\hline 1 & Baik & 20 & 67 \\
\hline 2 & Tidak Baik & 10 & 33 \\
\hline & Total & $\mathbf{3 0}$ & $\mathbf{1 0 0}$
\end{tabular}

Tabel diatas dapat dilihat distribusi frekuensi responden berdasarkan dari hasi dukungan keluarga mayoritas pasien mengalami dukungan keluarga yang baik sebanyak 20 jiwa(67\%) dan sedangkan minoritas dukungan keluarga yang tidak baik sebanyak 10 jiwa (33\%).

Tabel 3. Distribusi Frekuensi Kualitas Hidup Pasien Gagal Ginjal Kronik Yang Menjalani Tindakan Hemodialisa di RSU Royal Prima Medan Tahun 2019

\begin{tabular}{llll}
\hline No & $\begin{array}{l}\text { Kualitas } \\
\text { Hidup }\end{array}$ & $\begin{array}{l}\text { Jumlah } \\
(\mathbf{n})\end{array}$ & $\begin{array}{l}\text { Persentase } \\
(\boldsymbol{\%})\end{array}$ \\
\hline 1 & Baik & 18 & 60 \\
\hline 2 & Cukup & 7 & 23 \\
\hline 3 & Kurang & 5 & 17 \\
\hline & Total & $\mathbf{3 0}$ & $\mathbf{1 0 0}$ \\
\hline
\end{tabular}

Tabel 4. Hubungan Dukungan Keluarga Dalam Upaya Meningkatkan Kualitas Hidup Pasien Gagal Ginjal Kronik Yang Menjalani Hemodialisis di RSU Royal Prima Medan Tahun 2019

\begin{tabular}{|c|c|c|c|c|c|c|c|c|c|}
\hline \multirow{3}{*}{$\begin{array}{l}\text { Dukungan } \\
\text { Keluarga }\end{array}$} & \multicolumn{4}{|c|}{ Kualitas Hidup } & \multirow{2}{*}{\multicolumn{2}{|c|}{ Kurang }} & \multirow{2}{*}{\multicolumn{2}{|c|}{ Total }} & \multirow[t]{3}{*}{ P-Value } \\
\hline & \multicolumn{2}{|c|}{ Baik } & \multicolumn{2}{|c|}{ Cukup } & & & & & \\
\hline & $\mathbf{n}$ & $\%$ & $\mathbf{n}$ & $\%$ & & $\%$ & $\mathbf{N}$ & $\%$ & \\
\hline Tidak Baik & 8 & 27 & - & - & 2 & 6,7 & 10 & 33 & $\mathbf{0}^{\prime}$ \\
\hline Baik & 7 & 23,3 & 10 & 33,3 & 3 & 16,7 & 20 & & $0,0<0$ \\
\hline
\end{tabular}

Tabel 4 menunjukkan bahwa pada dukungan keluarga tidak baik terdapat ada 10 jiwa (33\%) dengan 8 jiwa (27\%) memiliki kualitas hidup baik, dan 2 jiwa $(6,7 \%)$ mengalami kualitas hidup kurang baik. Sedangkan pada dukungan keluarga yang baik terdapat 20 jiwa responden dengan 7 jiwa $(23,3 \%)$ memiliki kualitas hidup baik, 10 jiwa $(33,3 \%)$ memiliki kualitas hidup cukup dan 3 jiwa $(16,7 \%)$ memiliki kualitas hidup yang kurang.

Berdasarkan hasil perhitungan uji chisquare, diperoleh hasil p-value $0,020<0,05$ yaitu Ha diterima dan Ho ditolak yang artinya hubungan yang signifikan yang terjadi terhadap dukungan keluarga dalam upaya meningkatkan tingkat kualitas hidup pasien GGK yang melakukan tindakan terapi hemodialisa Di RSU Royal Prima Medan Tahun 2019.

\section{PEMBAHASAN}

Anlisa Univariat

Karakteristik berdasarkan umur mayoritas yang menderita GGK Yang
Tabel diatas dapat dilihat distribusi frekuensi responden berdasarkan kualitas hidup mayoritas pasien yang mengalami kualitas hidup yang baik sebanyak 18 jiwa (60\%) dan minoritas kualitas hidup yang cukup 7 jiwa (23\%) dan kualitas hidup kurang sebanyak 5 jiwa (17\%).

\section{Analisa Bivariat}

Analisa Bivariat dibuat berfungsi sebagai untuk melihat adanya Dukungan Keluarga Dalam Upaya Meningkatkan Kualitas Hidup Pasien GGK Yang Menjalani Hemodialisa Di RSU Royal Prima Medan Tahun 2019, Maka diperoleh sebagai berikut: 
selalu memberikan dukungan kepada pasien untuk mencapai kerberhasilan dalam pelaksanaan hemodialisa dan dukungan kelurga tidak baik sebanyak 10 orang $(33,3 \%)$.

Menurut hasil penelitian Ratna (2010) menyatakan dukungan kelurga ialah hal yang terpenting bagi seseorang ketika seseorang ketika menghadapi masalah kesehatan atau sakit untuk mengurangi beban akan penyakit yang di deritanya karena akan ada perubahan fisik yang dialami akibat penyakit yang diderita dan untuk meningkatkan kualitas hidup seseorang. Berdasarkan penelitian Bomar (2004) menyatakan bahwa dukungan Keluarga ialah tindakan atau sikap yang harus dilakukan oleh keluarga kepada seseorang yang mengalami masalah kesehatan atau salit baik dalam bentuk, dukungan informasi, dukungan instrumental, dukungan penghargaanm dukungan emosional maupun dukungan moral.

\section{Distribusi Frekuensi Kualitas Hidup}

Berdasarkan hasil penelitian 30 responden dapat di lihat distribusi frekuensi karakteristik kualitas hidup responden berdasarkan tingkatan kualitas hidup yaitu kualitas hidup baik sebanyak 18 jiwa (60\%), hal ini biasanya terjadi dikarenakan selalu adanya dukungan keluarga yang di dapatkan oleh responden yang menderita penyakit GGK saat mereka lagi menjalani terapi hemodialisa kualitas hidup cukup sebanyak 7 jiwa $(23,3 \%)$, kualitas hidupkurang sebanyak 5 jiwa $(16,7 \%)$.

Berdasarkan hasil penelitian Nurchayati (2010), kualitas hidup ialah pendapat seseorang terhadap posisinya dalam kehidupan serta di pengaruhi oleh faktor kebudayaan. Norma dan nilai yang terdapat dalam kebudayaan seseorang tersebut, keinginan untuk meningkatkan kualitas hidup seseorang.

\section{Hubungan Dukungan Keluarga Dalam Upaya Meningkatkan Kualitas Hidup Pasien Gagal Ginjal Kronik Yang Menjalani Hemodialisis Di RSU Royal Prima Medan Tahun 2019}

Berdasarkan hasil perhitungan uji chisquare, diperoleh hasil p-value $0,020<0,05$ yaitu Ha diterima dan Ho ditolak yang artinya terdapat hubungan yang signifikan terhadap dukungan keluarga dalam upaya meningkatkan kualitas hidup pasien GGK yang menjalani hemodialisa Di RSU Royal Prima Medan Tahun 2019.

Berdasarkan dari hasil penelitian yang di lakukan oleh peneliti terhadap 30 responden yang ada unit henmodialisa dengan dukungan keluarga baik diperoleh hasil sebanyak 20 jiwa $(66,7 \%)$, dukungan keluarga tidak baik didapatkan hasil sebanyak 10 orang $(33,3 \%)$ dan kualitas hidup baik diperoleh hasil sebanyak 18 jiwa (60\%), kualitas hidup cukup sebanyak diperoleh hasil sebanyak 7 jiwa $(23,3 \%)$, kualitas hidup kurang 2 jiwa (16,7\%).

Hasil penelitian yang mendukung, penelititian Zurneli (2012) yang meneliti tentang Dukungan Kelurga Untuk Meningkatkan Kualitas Hidup Pasein GGK Yang Menjalani Hemodialisa di RSUD Arifin Achmad Pekanbaru didapatkan hasil $\mathrm{p}$-value $=0,002 \quad(\mathrm{p}<0,005) \quad$ yang artinya bahwa ada terdapat sebuah hubunga terjadi antara Dukungan Kelurga Dalam Meningkatkan Kualitas Hidup Pasien GGK Yang Menjalani Hemodialisa

Hasil penelitian ini diperkuat oleh adanya penlitian yang di lakukan oleh candra (2009) yang menyatakan bahwa dengan adanya dukungan keluarga akan terjadinya sebuah dukungan kelurga ,maka pasien akan merasa nyaman,senang serta tenang dan lebih kuat menerima setiap keadaan fisiknya sehingga akan memberikan dampak yang sangat baik terhadap tingkat kualitas hidup pasien GGK dan dapat mempercepat proses penyembuhan penyakit yang di hadapinya. Hasil penelitian ini di kuatkan oleh Effendi (2009) yang berpendapat bahwa dukungan kelurga sangat penting dalam tahap perawatan kesehatan, mulai dari tahap peningkatan kualitas hidup, peningkatan kesehatan, pencagahan, dan pada tahap pengobatan dan untuk

Menurut penelitian Setyowati dan Arita (2010) Meperkenalkan atau menjelaskan masalah kesehatan kepada setiap anggota keluarga yang mengalami masalah kesehatan atau sakit berarti harus juga mengenal fakta-fakta dari setiap permasalahan kesehatan atau penyakit yang meliputi seperti pengertian, gejala dan tanda dan factor yang menyebabkan bisa timbulnya penyakit tersebut. disini dapat di lihat semakin banyak kelurga dapat mengetahui atau mengerti permasalahan yang terjadi pada penyakit penderita GGK 
yang menjalani tindakan hemodialisa, keluarga harus dapat mengetahui apa yang harus diperbuat dalam meningkatkan kualitas hidup pasien GGK.

Menurut penelitian Ibrahim (2006), aspek kualitas hidup tertinggi pada pasien GGK ialah suatu kepuasan seseorang atas dukungan yang diterima dari keluarga dekat maupun keluarga jauh kerabat, maupun teman serta relasi yang baik antara pasien GGK yang melakukan tindakan hemodialisa maka tindakan tersebut akan memotivasi pasien untuk menjadi lebih baik.

\section{KESIMPULAN}

Berdasarkan hasil penelitian mengenai dukungan keluarga dalam upaya meningkatkan kualitas hidup pada pasien GGK yang menjalani hemodialisa di RSU Royal Prima Medan Tahun 2019, maka dapat ditarik sebuah kesimpulan sebagai berikut:

1. Distribusi karakteristik berdasarkan umur mayoritas respon dengan gejala gagal ginjal kronik berumur21-56tahun dengan jumlah 17jiwa $(56,7 \%)$ dan minoritas berumur57-73 tahun dengan jumlah 13 $(43,3 \%)$. Umur tidak memiliki sebuah hubungan dengan timbulnya penyakit gagal ginjal kronik. Karak teristik berdasarkan jenis kelamin mayoritas respon dengan penyakit gagal ginjal kronik berjenis kelamin perempuan dengan jumlah 16 jiwa $(53,3 \%)$ dan minoritas responden laki-laki dengan jumlah14 jiwa (46,7\%).peneliti menemukan bahwa jenis kelamin perempuan lebih cenderung mengalami penurunan kualitas hidup pada saat menjalani hemodialisa.

2. Hasil penelitian dukungan keluarga dalam upaya untuk meningkatkan kualitas hidup pasien yang menderita penyakit GGK yang menjalani tindakan hemodialisa didapatkan hasil mayoritas baik sebanyak 20 jiwa $(66,7 \%)$, dan dukungan kelurga minoritas tidak baik diperoleh hasil sebanyak 10 jiwa $(33,3 \%)$.

3. Hasil penelitian yang dilakukan diperoleh hasil distribusi frekuensi karakteristik kualitas hidup responden berdasarkan tingkatan kualitas hidup yaitu mayoritas responden berkualitas hidup baik sebanyak 18 jiwa (60\%),kualitas hidup yang cukup sebanyak 7 jiwa (23,3\%), dan Minoritas berkualitas hidupkurang sebanyak 5 jiwa $(16,7 \%)$.

4. Hasil Penelitian didapatkan sebuah hubungan yang signifikan terhadap pemberian dukungan keluarga dalam upaya meningkatkan kualitas hidup pasien GGK yang menjalani tindakan hemodialisa Di RSU Royal Prima Medan Tahun 2019.

\section{SARAN}

Diharapkan responden dapat menerima keadaannya dan dapat menjalani proses hemodialisa secara teratur. Diharapkan pada tempat penelitian dapat meningkatkan pelayanan kesehatan dan mensosialisasikan pendidikan kesehatan tentang dukungan keluarga dalam upaya meningkatkan kualitas hidup pasien gagal ginjal kronik yang menjalani hemodialisa. Hendakanya peneliti selanjutnya meneliti tentang penelitian pada penyakit yang lain denganvariabel yang sama.

\section{DAFTAR PUSTAKA}

Afiyanti, Y. \& Rachmawati, I N. (2014). Metodologi Penelitian Kualitatif Dalam Riset Keperawatan. Jakarta: Rajawali Pers.

Agoes, A., Agoes, A., \& Agoes, A. (2018). Penyakit Di Usia Tua. Jakarta: EGC.

Bomar. (2004). Promating Health Families Applying Family Researchand Therapy To Nursing Practice. Philadelpia: W.R Saunders.

Daryani. (2011). Faktor-Faktor Yang Mempengaruhi Keputusan Inisiasi Dialisis Pasien Gagal Ginjal Tahap Akhir Di RSUP. Soeradji Tirtonegoro.

Esi, S Kamasita., Suryono., N, Yudha., Dkk. (2018). Pengaruh Hemodialisa Terhadap Kinetik Segmen Ventrikel Kiri Pada Pasien Penyakit Ginjal Kronik Stadium V. URL: https://jurnal.unej.ac.id/index.php/NLJ/ articele/download/6506/5674.

Hidayat, A A. (2009). Metode Penelitian Dan Teknik Analisis Data.Jakarta: SalembaMedika.

Ibrahim, K. (2009). Quality Of Life Of Patient With Cronic Renal Failure Undergoing Hemodialysis. Bandung: The Kidney Disease outcomes quality 
intiative (2012). URL:

http://www.juveska.com.gagal-ginjalkronik-atau-kkd.

Kemenkes (Kementerian Kesehatan Republik Indonesia). (2018). Cegah Dan Kendalikan Penyakit Ginjal Dengan Cerdik Dan Patuh. URL: http://www.depkes.go.id/article/view/18 030700007/cegah-dan-kendalikanpenyakit-ginjal-dengan-cerdik-danpatuh.html.

Nofitri. (2009). Kualitas Hidup Penduduk Dewasa. URL: http:www.lontar.ui.ac.id.

Notoatmodjo, S. (2012). Metodologi Penelitian Kesehatan. Jakarta: RinekaCipta.

Nursalam. (2008). Konsep Dan Penerapan Metodologi Penelitian Ilmu Keperawatan. Jakarta: SalembaMedika.

Ratna. W. (2010). Sosiologi Dan Antropologi Kesehatan. Yogyakarta: Pustaka Rihama.

Sitinjak, R R. (2013). Konsep Dan Teknik Pelaksanaan Riset Keperawatan. Medan: Bina Media Perintis.

Smeltzer, S, \& Bare. (2002). Buku Ajar Keperawatan Medikal Bedah. Jakarta: EGC

Sri, S, dan Umi, S. (2016). Perbedaan Kualitas Hidup Pasien Gagal Ginjal Kronik Ditinjau Dari Tingkat Pendidikan, Frekuensi Dan Lama Hemodialis Di RSUD Goeteng
Taroenadibrata Purbalingga. URL: http://jurnalnasional.ump.ac.id/index.p $\mathrm{hp} /$ medisains/article/viewfile/1055/212 4.

WHO. (2004). The world health organization quality of life (WHOQOL) -BREF. URL: https://www.who.int/substance_abuse/r esearch tools/en/indonesian whoqol.p $d f$

WHOQOL-BREF. (1996). Introduction, administration, scoring, and generic version of the assessment. 13-18. URL: https://www.who.int/mental_health/med ia/en/76.pdf.

Willis, SS. (2009). Konseling Keluarga (Family Counseling). Bandung: Alfabeta.

Zedeh, K, Koople J. D., and Block, G. (2003). Association Among SF-36 Quality Of Life Measure and Nutrution Hospitalization and Mortality in Hemodialisis. American journal of Kidney Diseas.

Zurmeli., Bayhakki., \& Utami G T. (2015). Hubungan Dukungan Keluarga Dengan Kualitas Hidup Pasien GGK Yang Menjalani Terapi Hemodilaisa Di RSUD Arifin Achmd Pekanbaru. Jurnal Kesehatan Masyarakat. 2(11), 670-675).

$U R L:$ https://jom.unri.ac.id/index.php/JOMPS IK/article /view/5172. 